\title{
Dynamics of bamboo design and build collaborations
}

Helen Norrie

University of Tasmania, Australia

School of Architecture \& Design

Helen.Norrie@utas.edu.au

Philippa Grainger

University of Tasmania, Australia

School of Architecture \& Design

pip.grainger@live.co.uk

Jed Long

University of Tasmania, Australia

jed.long@utas.edu.au
Harriet Georgina Elliott

University of Tasmania, Australia

School of Architecture \& Design

harriet.elliott@live.com.au

Nici Long

Sydney University, Australia

nici@caveurban.com

\section{Tracey Woods}

University of Tasmania, Australia

School of Architecture \& Design

Tracey.Woods@utas.edu.au

\begin{abstract}
Design and construction of a temporary bamboo structure provided the vehicle to explore live and interactive design-led research, extending collaborative partnerships and forging new relationships. Designed for two events of contrasting scale as part of the Dark Mofo annual arts festival hosted by the Museum of Old and New Art (MONA) in Hobart, Tasmania, the project drew on an extensive portfolio of research into traditional and contemporary bamboo structures complied by Sydney-based architecture practice, Cave Urban. It extended Cave Urban's previous partnerships with Taiwanese artist, Wang Wen Chih, and involved collaboration between Cave Urban and students from the University of Tasmania (UTAS) School of Architecture \& Design and Tasmanian College of the Arts (TCotA), and on-site assistance from the MONA events construction team.

Construction over a three-week process involved design research that provided new knowledge into bamboo structures and developed new process of Learning By Making as a form of collaborative research-based teaching. Interaction between the team of 25 people shifted between modes of open/closed and flat/hierarchical collaboration, in a dynamic process that lent new definition to the idea of 'live' projects. Design-led research provided the opportunity for an equal number of students and expert collaborators, facilitating an opportunity to explore a master/apprentice model, to expanded practical and theoretical knowledge and expertise through the design and construction of a temporary civic event space.
\end{abstract}

Keywords: temporary, bamboo, pavilion, collaboration, interactive.

To cite this article:

Norrie, H., Elliott, H. G., Grainger, P., Long. N., Long, J., Woods, T. (2017). Dynamics of bamboo design and build collaborations. The Journal of Public Space, 2(3), Special Issue, 85-92, 93-102, DOI: 10.5204/jps.v2i3. II8

This article has been peer-reviewed and accepted for publication in The Journal of Public Space. Please see the Editorial Policies under the 'About' section of the journal website for further information.

This work is licensed under a Creative Commons Attribution - Non Commercial 4.0 International License https://creativecommons.org/licenses/by-nc/4.0/ 


\section{Dynamics of bamboo design/build collaboration}

Collaborative design research between the University of Tasmania (UTAS) School of Architecture \& Design at the and Sydney-based architectural practice Cave Urban was central to the design and construction of a bamboo "Hothouse" pavilion for the Dark Mofo arts festival in Tasmania. A process of 'applied enquiry' was central to the project, which expanded Cave Urban's extensive research into traditional and contemporary bamboo structures.' The project also provided a unique situated learning experience for the team, extending the Learning My Making (LBM) practices that are central to the UTAS Architecture and Design curriculum.

\section{Bamboo design research}

Cave Urban's ongoing design research into bamboo explores the potential of bamboo as a viable building material in Australia through a series of temporary pavilions. Working with Taiwanese artists Wang Wen Chih and engineer Jeremy Sparks, Cave Urban challenge the lack of provision in the Australian building codes for bamboo structures. The Hothouse drew on and extended Cave Urban's extensive portfolio of research into traditional and contemporary bamboo structures, and produced new knowledge through design research methods that can be understood in terms of Christopher Frayling's tripartite model of research into/for/through design. ${ }^{2}$ Research into design examined bamboo, drawing on precedents and analyzing structural and construction systems, while research for design involved a critical investigation of pavilions for performance and public events, both historical and contemporary. The development of prototypes across a range of scales allowed for formal testing of the structural and aesthetic ideas, providing an understanding of the relationship between structure and aesthetics, through processes of research through design. Scale models and full-size prototypes were used to evaluate the performance of the structural system, and assumptions were then tested throughout the building process, and examined further during the dismantle process.

\section{Situated Learning By Making}

The Hothouse typified the values of the School's LBM programme, which integrates design and building technology through a process of experience-based or 'situated' learning. ${ }^{3}$ LBM projects typically involve groups of students working together to design and construct projects, with staff acting as facilitators who provide guidance and practical demonstration of construction processes. ${ }^{4}$ The Hothouse employed new modes of engagement between students and supervisors, providing new knowledge into the School's LBM pedagogy and design research portfolio.

The project provided a model of research-based teaching that was characterised by a twoway engagement between students and supervisors. 5 The team of bamboo specialists,

\footnotetext{
' Ron Griffiths, "Knowledge production and the research-teaching nexus: the case of the built environment disciplines," Studies in Higher Education, 29, 6 (2004): 717.

2 Frayling, Christopher. "Research in Art and Design", Royal College of Art Research Papers series, I(I) (1993).

${ }^{3}$ Lave, Jean, and Etienne Wenger, Situated Learning: Legitimate Peripheral Participation. Cambridge: Cambridge University Press, (1991).

${ }^{4}$ Wallis, Louise. Learning-by-Making: Design-build studios at the School of Architecture at the University of

Tasmania (Masters thesis, University of Tasmania, 2005).

${ }^{5}$ Griffiths, "Knowledge production”, 722.
} 
builders, designers and artists created a platform for interdisciplinary collaborative design-led research (or research through design) which was characterised by an iterative process of testing and experimentation. The equal ratio of students to supervisors resulted in a unique master/apprentice model. Students were mentored by a 'master' designer-maker, acting as their assistant or 'apprentice,' developing a broad range of skills including research, experimental design and construction. This developed the students' the skills and confidence to take an increasing role in exploration, decision-making and leadership. This process provided a unique Workplace Integrated Learning (WIL) opportunity, which bridged design research with architecture and construction practices.

\section{Interactive and collaborative design research}

The interactive design-led research central to the Hothouse diverged from traditional procurement methods, where the design is developed through sketches and models then documented in general arrangement and detail drawings before implementation on site. The project was structured around four intensive workshops: research and experimentation (grounding), design (ideation), on-site testing and construction (iteration) and dismantle (reflection). ${ }^{6}$ Design principles for the overarching spatial and structural strategy were developed through explorative model-making and iterative prototype testing, which was developed throughout the 23-day design/build phase. Each of the stages of site set out, column erection, beam construction, roof cladding, and layering of internal secondary structure involved a high degree of iteration and experimentation.

Workshop I: GROUNDING - research and experimentation

The first workshop was aimed at the developing the students' understanding of the structural properties and formal possibilities of bamboo through research and practical experiments. Documentation of site conditions and the preparation of site drawings developed an understanding of the site context, and discussions with Cave Urban via Skype mirrored the traditional supervision and mentoring that would occur in practice. Iterative feedback highlighted to the students the need for precision and detail, beyond that of a typical speculative design studio.

\section{Workshop 2: IDEATION - design}

The second workshop, which focused on the development of the founding design idea, also served as a basic training session in bamboo construction. Cave Urban lead the collaborative experimentation of ideas with the development of $1: 20$ scale models and a $1: 3$ scale prototypes, introducing the UTAS team to research through design processes of trial and error that would become central to the on-site design and construction. This lead to an appreciation the overlapping of structural and sculptural qualities of bamboo, and the exploration of alternatives to complex and time-consuming traditional rope-tied joints. This workshop also cemented the interpersonal relationships, developing an understanding of each other's expertise, and the developing the team dynamics. All team members worked together to negotiate the content and format of the drawings for the client presentation, with Cave Urban leading the process and the UTAS team assisting in the production of drawings, renders and montages, and participating in the decision-making about graphic content and format, in a manner that mirrored an architectural practice scenario.

\footnotetext{
${ }^{6}$ John Zimmerman, Jodi Forlizzi and Shelley Evenson. "Research through design as a method for interaction design research in HCl”, Carnegie Mellow University Research Showcase @CMU, (2007, I).
} 

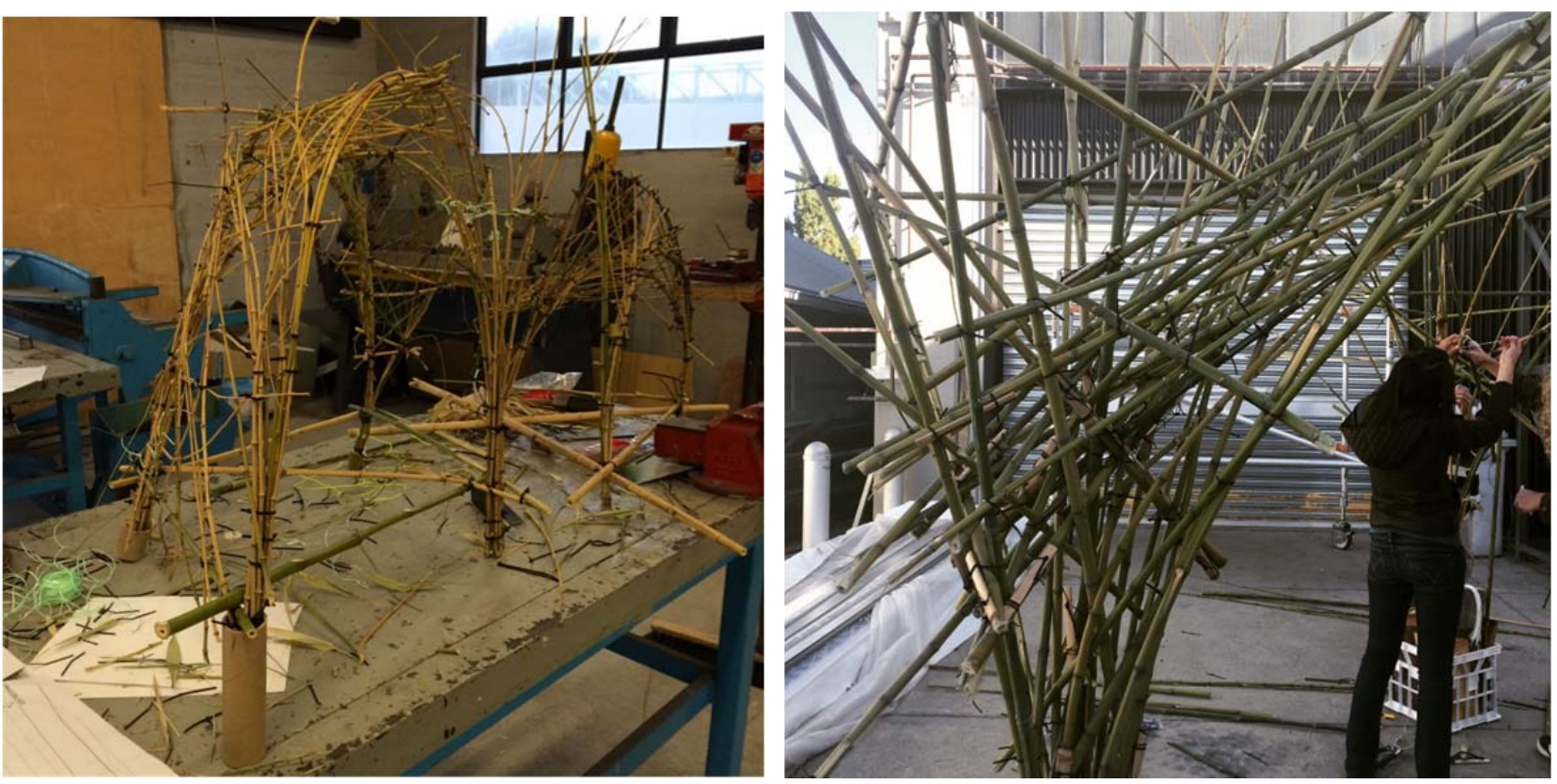

Figure I : Scale models testing bamboo systems (left) and detail (right). Images: Helen Norrie.
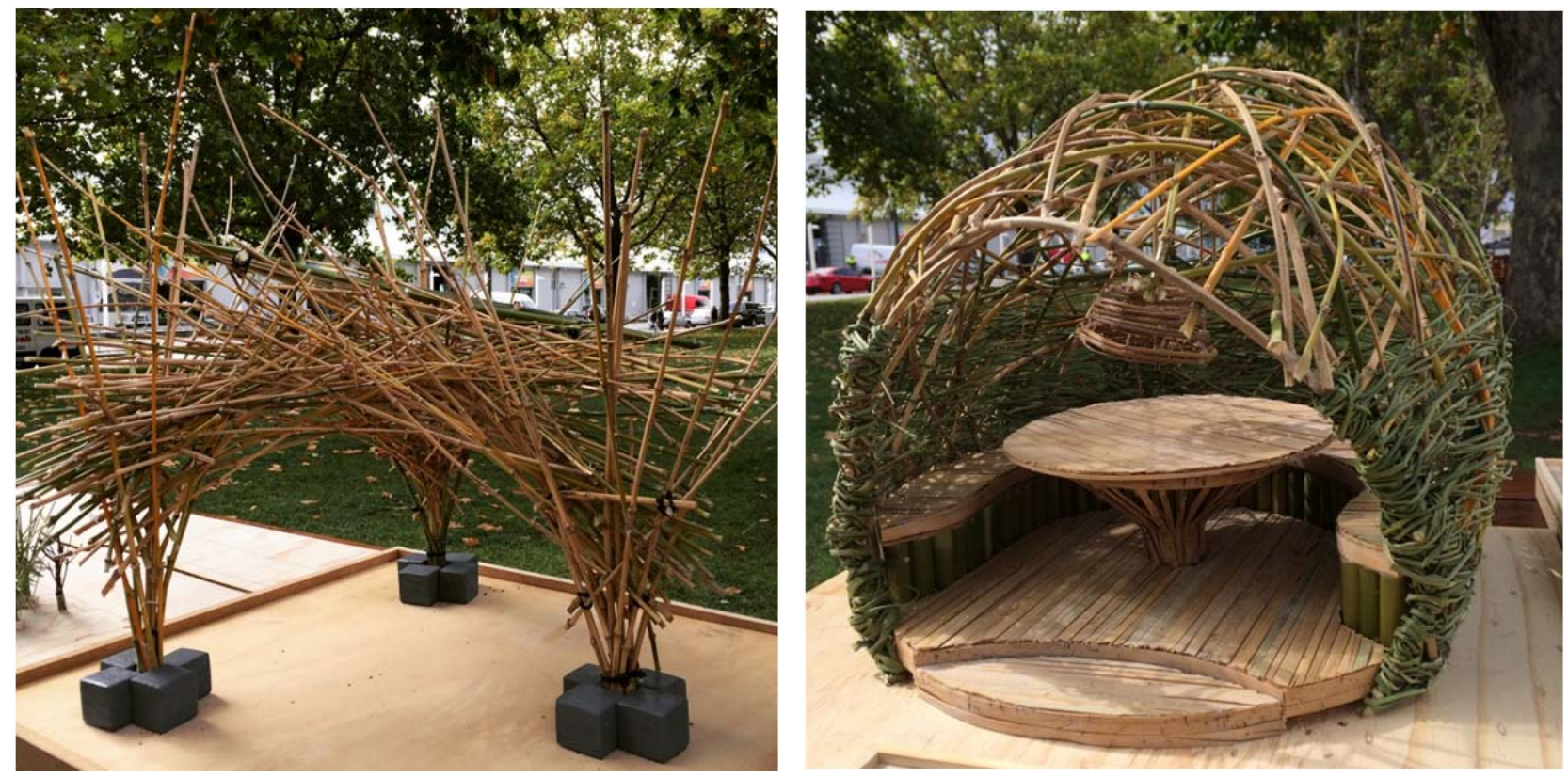

Figure 2: Scale models of structural bay of canopy (left) and pods (right) Images: Helen Norrie.

The brief to create a bamboo structure that could serve both an intimate setting for a thinktank discussion and a large-scale interactive festival event, which was warm and dry in the middle of winter, was wildly optimistic. The conceptual idea of the Hothouse as a hybrid of a bamboo forest and a Gothic cathedral was developed into a strategy for a series of triangular bays that formed the scaffold for the structure of the 40-metre long canopy that would become the backdrop for the Dark Mofo Winter Feast. A 'conversation pit' with a hearth and

96 | The Journal of Public Space, 2(3), 2017 | Special Issue | ISSN 2206-9658

(C) Queensland University of Technology 
four independent cocoon-like pods positioned in the central bay of the canopy provided a more intimate setting for the smaller-scale think-tank event.

\section{Workshop 3: ITERATION - on site testing and construction}

Experimentation and testing continued on site, with the construction process becoming an exercise in large-scale prototyping to test and experiment with different structural and formal ideas. Understanding the physical properties of the bamboo was central to the process. Four different species of bamboo were used, and it was necessary for the team to be able to visually identify the different types and to understanding of the specific structural characteristics, particularly flexibility and strength, so this could be factored into the design decision-making. The bamboo was not as flexible as was initially anticipated, and after an exhaustive process of experimentation, the initial strategy of forming each of the five bays from a series of overlapping 'Gothic' arches, was replaced by structural system of columns and curved beams.

Each stage of the assembly involved a process of testing to see what worked, and adapting the overall strategy and the detail of each component to suit. This required an evaluation of structural systems, techniques, formal composition and detail, highlighting the nexus between structure and aesthetics that is central to bamboo construction. This required a coordinated approach, with one team focusing on the construction of the elements and the other on the effect that each element was having on the overall structure, and then adjusting the overall design to suit. This created an ongoing process of testing and critical reflection, continually building knowledge about the performance of the structural system, with each team member becoming an active agent in the critical analysis of the design process.
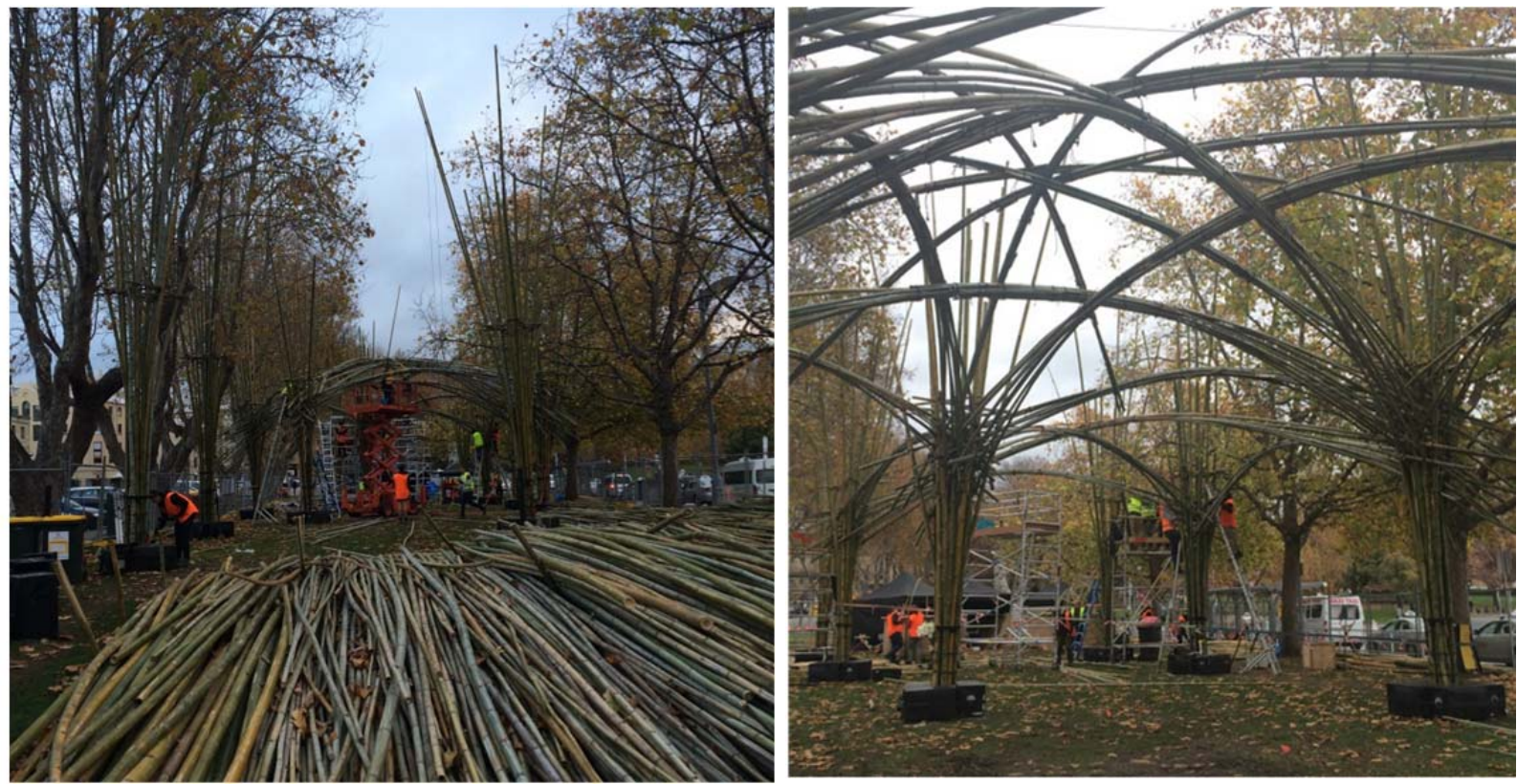

Figure 3: Central bay of canopy (left) and column and beam junction (right). Images: Helen Norrie. 

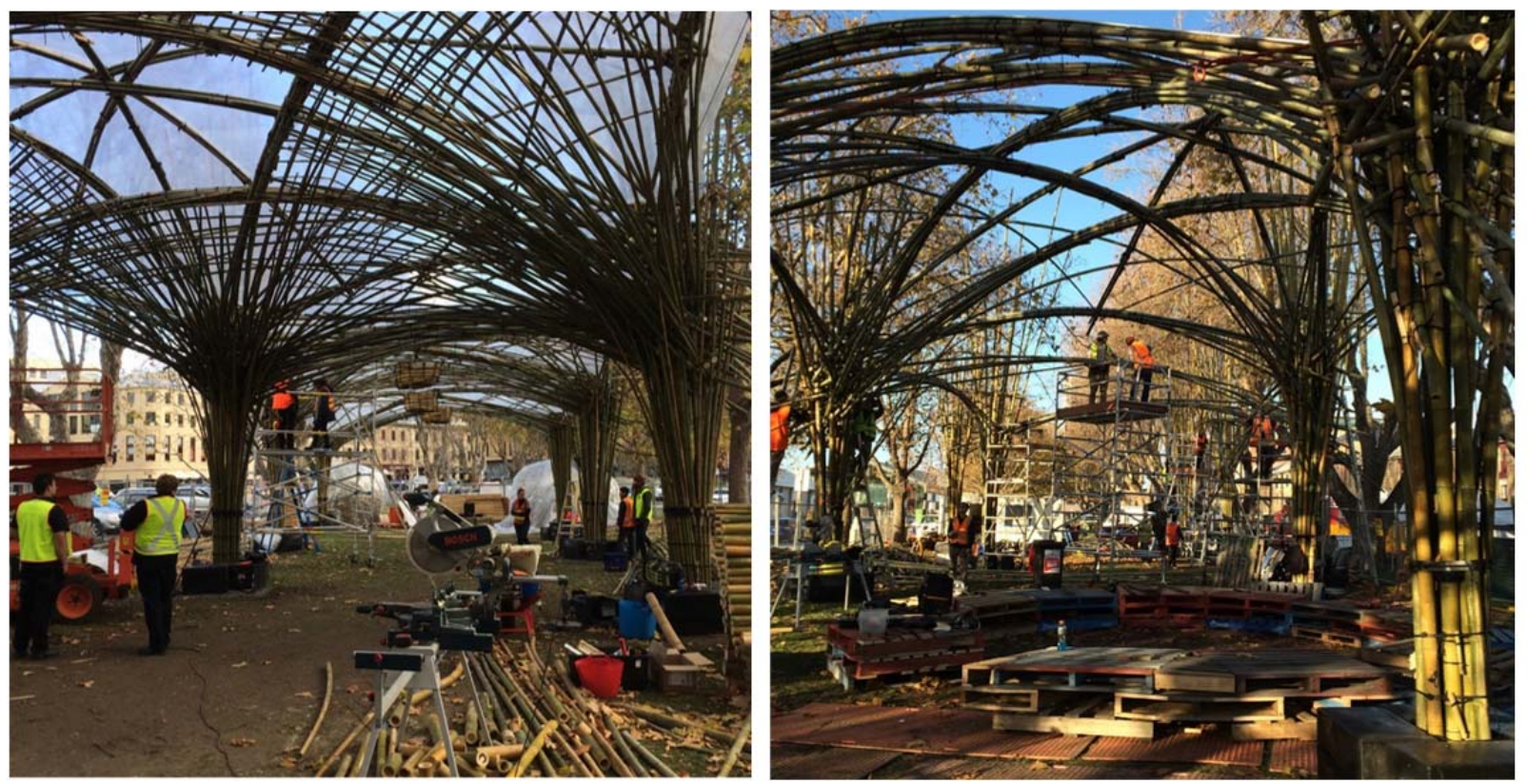

Figure 4: Roofing complete on central bay (left) and end bay (right). Images: Helen Norrie.

This process of reflection-in-action is central to Cave Urban's design/build/research process and it creates a dynamic and reflexive form of praxis, expanding the limits of knowledge to create projects that are as much experimental installations as they are ideas for buildings. ${ }^{7}$

Cave Urban embrace experimentation as part of the process:

Our philosophy as a firm is to use research to investigate a different approach to architecture that tests in situ what we can and can't do with a material. At times that means two steps forward and one step back, but we find this process allows for the best result in a design that utilise non standardised materials. For us design is all about flexibility and being open to the notion of new possibilities, if an opportunity presents itself. For those used to a more conventional way of doing things, this can be at times challenging and frustrating. ${ }^{8}$

Workshop 4: REFLECTION - dismantle and review

Dismantling the temporary structure completes the research, with the strength tests carried out to examine the possible loads that the structure could carry. This information was fed back to the engineering team, and will inform the next project. The construction process was also documented by the team, including drawings of jointing techniques which can be shared on future projects.

\footnotetext{
${ }^{7}$ Fraser, Murray. Design Research in Architecture: an overview. (Farnham, England; Burlington, USA: Ashgate, 2013).

${ }^{8}$ Personal correspondence with Cave Urban, August, 2015.
}

98 | The Journal of Public Space, 2(3), 2017 | Special Issue | ISSN 2206-9658

(C) Queensland University of Technology 

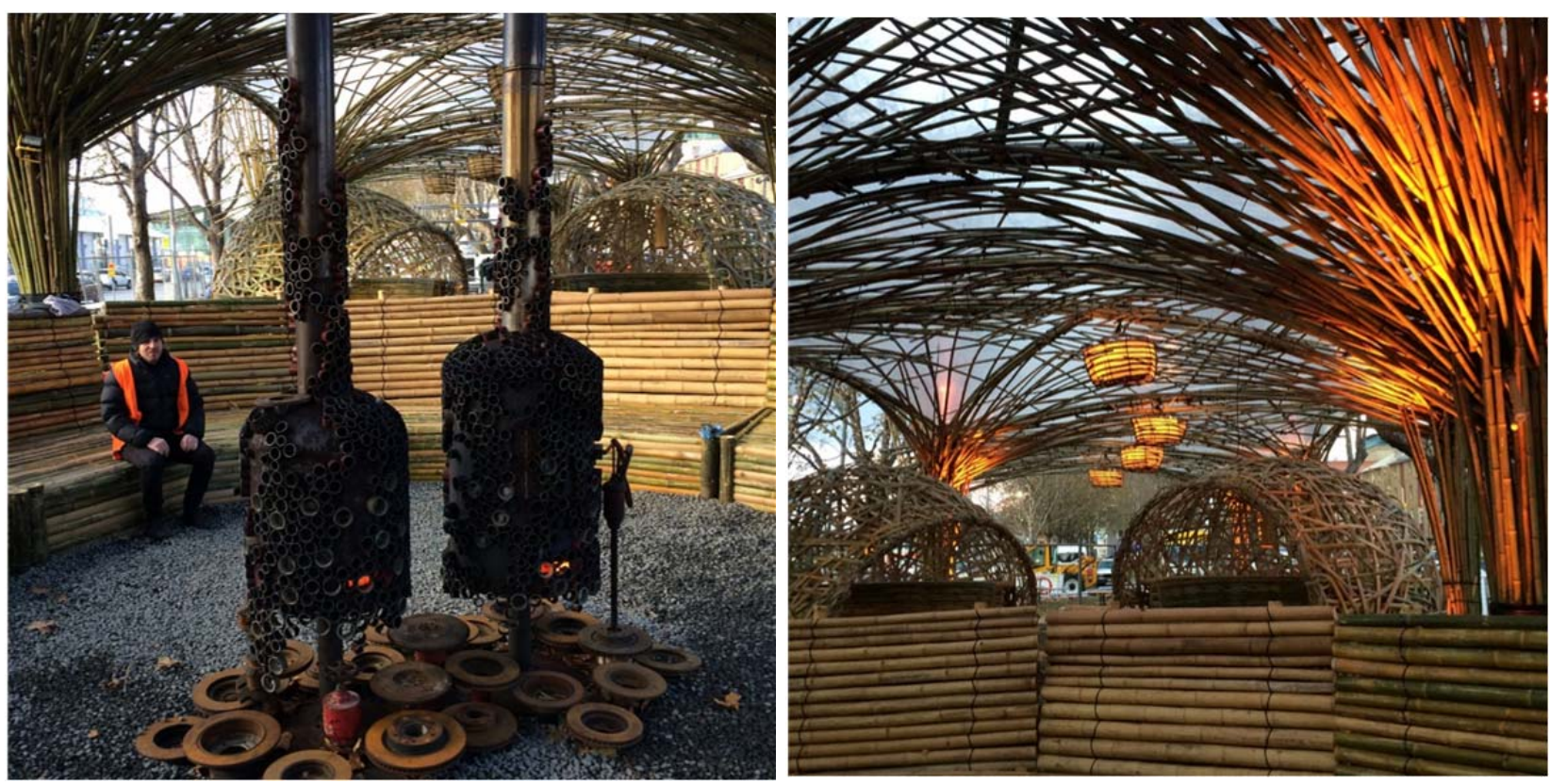

Figure 6: The conversation pit (left) and pods under canopy (right). Images: Helen Norrie.

\section{Reflecting on design-led research}

Critically reflecting on the process of collaboration yields a further field of enquiry that extends the processes of research into/for/through design to include research about design, which 'enquires into what takes place when design is undertaken, and then seeks to find methods to improve or refine the observed activity.' 9 The process of grounding/ideation/iteration/reflection parallels the Design Council's Double Diamond Model of four phases of the design processes: discover, define, develop, and deliver. ${ }^{10}$ The discovery phase involves research that informs the definition of the project in the second phase, clarifying the project objectives and scope. The third stage involves the development of the project, testing ideas, evaluation, iteration and feedback, leading to the final project delivery. In the Hothouse project, the definition between discover/define/develop/deliver became blurred. Although the design was developed and presented to the client in the initial phase, new discoveries helped to continually redefine the direction, this reinforced the importance of the 'develop' stage as a process of iterative design research, which involved the constant refinement of the relationship between form and structure. This dynamic process was necessary to accommodate the unpredictable nature of the building material and the fast pace of the construction. This open-ended process provided opportunities for exploration, which allowed the form of the structure to evolve as discoveries about the material and construction process were revealed.

\footnotetext{
${ }^{9}$ Murray Design Research in Architecture, 95.

10 "A study of the design process". Design Council UK. Accessed October I, 2017. http://www.designcouncil.org.uk/sites/default/files/asset/document/ElevenLessons_Design_Council\%20(2).pd $\underline{f}$
} 


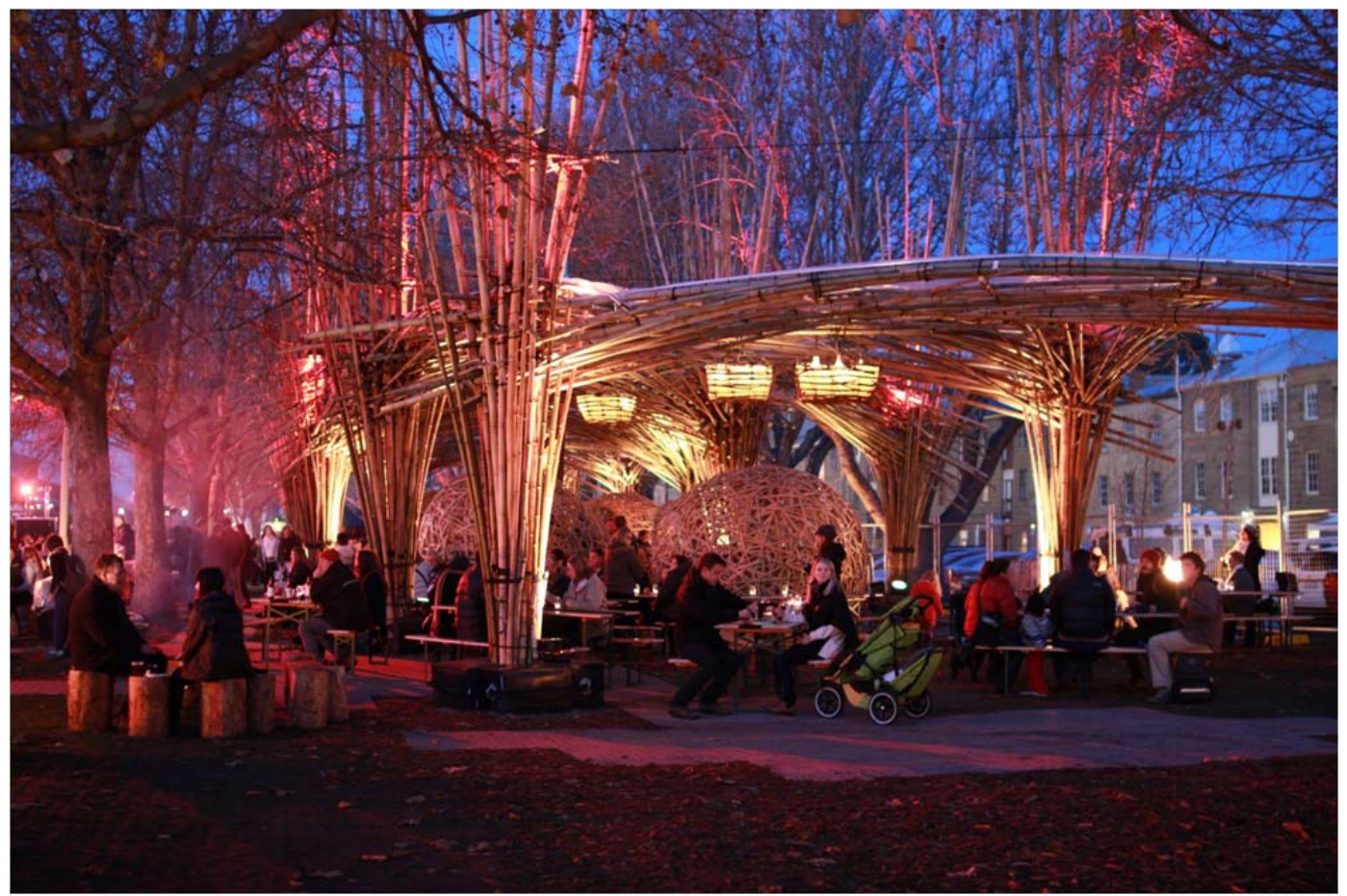

Figure 7: The Hothouse during the Dark Mofo Winter Feast.

\section{Reflecting on the interactive design research collaboration}

Analysis of the different modes of collaboration that were central to the project provides new knowledge and critical reflection on Learning By Making practices. Robert Verganti and Gary Pisano's definition of the intersecting scale of open/closed and flat/hierarchical structures provides a scaffold for analysis. Open collaboration allows for all group members to participate equally, whereas closed structures involve a selected group of participants. Flat structures encourage participation in decision-making by all group members, while hierarchical structures define particular decision makers. This results in four modes of collaboration: closed hierarchical (elite circle); open hierarchical (innovation mall); open and flat network (innovation community) and closed flat structures (consortium). "In the Hothouse, the collaborative relationships shifted along a sliding scale of open/closed and flat/hierarchical throughout the various phases of the project, and this process of transition was generally fluid and tacit rather than preconceived and directed.

During construction, the teams from Cave Urban and UTAS School of Architecture \& Design, were joined by volunteers from the UTAS Tasmanian College of the Arts (TCotA) and the MONA events construction crew. This meant that the ratio of skilled and experienced masters (bamboo specialists and construction crew) and apprentices (architecture and art students) was roughly one to one. All the tasks required teamwork, and each team was formed around the guidance and leadership of a master. As the students gained expertise and an understanding of the structural system, they transitioned from apprentice to master, and were able to mentor their peers. This resulted in more complex and fluid modes of collaboration, which shifted as team members developed skills and confidence.

" Verganti, Roberto, and Gary P. Pisano. "Which Kind of Collaboration Is Right for You?" Harvard Business Review 86, n. 12 (December 2008). 
Generally, collaboration was characterized by an open, flat structure developed through both a self-determining and predetermined (or presumed) hierarchy. However, at particular points it was necessary to delegate decision-making to a smaller group of people, which reshaped the open, flat structure to a temporary closed flat or hierarchical structure. The pace of the project, particularly in the initial stages, and the tentativeness of students to advance ideas, led to Cave Urban taking charge of the process by presenting the key ideas for testing and exploration. This created an open hierarchy, in that all group members were involved in a collaborative process that was led by Cave Urban. The complexity of the project, the number and varying skills of people involved and the tight timeframe also influenced the modes of collaboration. This lead to a shifting open/closed hierarchy that involved leadership from more engaged and proactive team members. On site, it was periodically necessary for 'executive decisions' about construction and aesthetics were made by Cave Urban, due to their experience and their ultimate responsibility for the project.

The difference between the investment of the architecture students in the project as a part of course work, and the art students' voluntary engagement in the project created a tacit hierarchy. However, the peer-to-peer collaboration eroded divisions as participants shifted position between 'master' and 'apprentice' and moved between tasks, mastering each and then mentoring others. This provided a dynamic, collaborative environment, that shifted between open/close and flat/hierarchy depending on the tasks at hand, and the initiative and skills of participants.

Interestingly, the art and architecture students approached the design-build process differently, with the art students operating from a perceived sense of 'freedom' to experience the project from a volunteer's perspective. The art students generally exhibited a willingness to freely experiment, drawing upon their rich background of fluid creativity, and confidence with open-ended exploration. Their voluntary engagement did not necessarily affect their commitment to the project, with several of the art students equally invested in the project and committed to their ongoing engagement. This positively impacted on perceived hierarchy, with the art students who regularly attended becoming a core part of the decision-making team.

In contrast, the architecture students were initially more tentative, in part because of project's close coupling with coursework, which fuelled a sense of responsibility for the final outcome, and a sense of urgency and efficiency that at times resulted in a reticence to allocate time towards 'unnecessary' trial and error. It was challenging for some of the architecture students to adjust to the experimental process of testing and 'on the spot' design and problem solving, to embrace a preparedness redo parts of the project to accommodate both structural and aesthetic issues, and to embrace the embryonic process that required them to take risks and experiment.

\section{Conclusion}

The collaboration with Cave Urban extended design research into bamboo structures, providing new knowledge about structural systems. The project also provided a new model of collaborative engagement for the UTAS School of Architecture \& Design Learning By Making programme. Cave Urban's experience of working with large teams of volunteers was invaluable, as they shepherded the participants' transition from apprentice to master collaborator. The iterative and experimental nature of the project presented a far more dynamic process than the architecture students were used to. It contrasted strongly with traditional design studio process that revolves around a rigid tutor to student discourse 
whereby a student produces work which is then critiqued by the tutor, providing instruction for additions, adaptions and changes. Compared with the structured studio environment, the experimental design-build process was characterized by a perceived lack of procedural clarity, due to the rapid evolution of construction techniques and the absence of explicitly structured relationships between collaborators.

The use of bamboo provided unique opportunities for learning about the relationship between structure and form. Bamboo is ductile, yet unpredictable, but does not fail catastrophically as its long fibres and natural structure are more akin to a combination between rope and steel. The use of mostly hand tools for construction and repetitive tasks with a low level of expertise allowed participants to build confidence and resilience in a safe environment. This helped to build an arena where the stakes were low in terms of risk, and the opportunities for experimentation were high. Establishing an overarching a structural and spatial strategy that allowed the details to be designed onsite, providing a framework for exploration that provided a great amount of scope and flexibility.

The project required on the spot problem solving, communication and decision making, and through this process teams were able to gain experience and resilience as part of the architectural process. Throughout the project the UTAS team's confidence with this new process developed, allowing them to become key members of the collaborative design-led research into bamboo structures They commented on how this process highlighted the need for confident and quick decision making, and the importance of communication within the team and the need to work strategically in order to meet the time frames of the project. They recognised the need to embrace the experimental nature of the project, and to value testing and trial and error as a research tool that expanded understanding of structural and spatial possibilities of bamboo construction.

Nici Long, from Cave Urban, observers that unlike traditional building processes, bamboo construction creates a unique, and striking, sense of harmony on site. As each individual develops skills and understanding of the system and processes, teams work collectively towards a common goal, and construction progresses through a series of simple repetitive tasks. She suggests that this creates a "hive mentality" with each person moving between tasks as required. Although the construction involves ostensibly simple and repetitive tasks, it is also an iterative and exploratory process that requires judgment to be constantly exercised to mediate between the structural and sculptural qualities. Throughout the process whole crew was directly involved in the dynamics of collaboration; they were intertwined in the complex, and sometime fraught, negotiations between design and construction.

Although the neither the process nor the actual project is necessarily replicable, its relevance defines the project as design research, with the dynamic nature of the process lending a new definition to the idea of 'live' projects. 12 The design-led research expanded practical and theoretical knowledge into bamboo structures, and provided new understandings for the pedagogy of situated learning that will continue to inform future projects collaborative design and build projects.

12 Zimmerman et al., "Research through design as a method for interaction design research in $\mathrm{HCl}$ " (2007, 7).

102 | The Journal of Public Space, 2(3), 2017 | Special Issue | ISSN 2206-9658

(c) Queensland University of Technology 